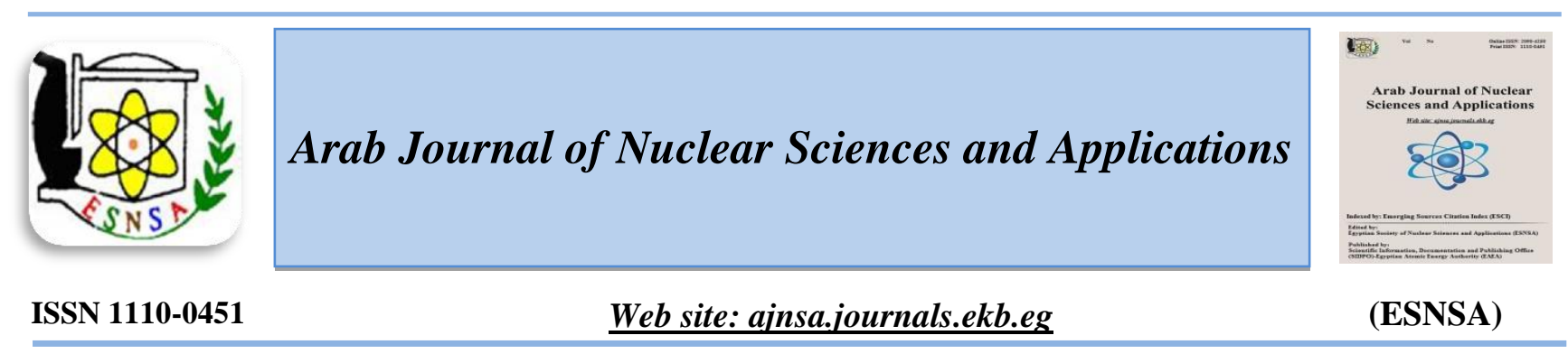

\title{
Investigation of the IAEA Benchmark Problem Using MCNP Code
}

Heba K. Louis

Safety Engineering Department, Nuclear and Radiological Regulatory Authority, Cairo, Egypt

Received $13^{\text {th }}$ Mar. 2018

Accepted $18^{\text {th }}$ Apr. 2018

\begin{abstract}
The "IAEA PWR benchmark problem" was intended to draw some conclusions about the accuracy of the different neutronic calculation codes used in the routine deterministic reactor calculation. The objective of this paper is to compare the results obtained using the MCNP computer code with previously obtained results, aiming to provide new reference solutions to the IAEA benchmark using the Monte Carlo method. The effective multiplication factor, the radial and axial assembly power distributions and the zone average group flux were calculated using Monte Carlo code (MCNP) version MCNPX 2.7.0. The MCNP results are compared with the results of deterministic calculations in two and three dimensions. Good estimates of effective multiplication factor and power distribution values were obtained. To assess the MCNP results, the collective percent error measures were determined and values calculated were less than $1 \%$. The results presented in the present study could be considered an accurate solution for the considered IAEA PWR benchmark problem and can be used as Monte Carlo method based reference for this problem.
\end{abstract}

Keywords: Multi-Group cross section; Multiplication factor; Power distribution; MCNP code

\section{Introduction}

Application of the Monte Carlo methods for simulating of neutron transport in nuclear reactors has more than fifty years of history [1]. Monte Carlo methods are very different from the deterministic transport methods. Deterministic computer codes are mainly based on diffusion theory model are using multi-group cross-section libraries. But the diffusion theory codes have some drawbacks because various geometric and analytical approximations are included, e.g. homogenization and multi-group cross-section treatment [2]. By contrast, the Monte Carlo technique can work with multi-group and continuous energy cross-section libraries; it simulates individual particle tracks of continuous energy through a given system of exact geometrical description, so it can provide a very accurate probabilistic transport solution [2]. Because Monte Carlo solutions represent an average of many sample histories, the statistical error or uncertainty is an equally important quantity as the actual results. As such, the statistical error is considered part of the answer [3, 4].

Moreover it can be used to decrease the running time of the calculation. Monte Carlo is a powerful modeling tool, which can be of great aid in the analysis of complex systems, due to its inherent capability of achieving a closer adherence to reality. MCNP code is one of the most popular particle transport codes used in nuclear reactors [5]. In this paper, Monte Carlo simulations have been done with MCNPX code version MCNPX 2.7.0 [6]

The aim of this paper is to set an accurate reference solution using Monte Carlo Method to the IAEA PWR (Pressurized Water Reactors) benchmark problem. This specific benchmark problem [7] was intended to measure the performance of neutronics calculation methods, drawing some conclusions about the accuracy of 
the different neutronic calculation codes used in the routine deterministic reactor calculation."The IAEA 3-D benchmark eliminates the part of the nuclear data; as the two groups cross section data is provided through the benchmark. Thus makes code comparison possible."[8]

Many research studies were performed for the before specified benchmark using deterministic method with different codes. In the following paragraphs some of these studies are mentioned.

Theler G., Clausse A. and Bonetto F.J. [9], have performed the solution of the "2D IAEA PWR benchmark" by using the Milonga code that solves the steady-state neutron diffusion equation with an arbitrary macroscopic cross section spatial distribution.

Imelda Ariani and Doddy Kastanya [10], at BATAN (Indonesia), have performed the evaluation of the "IAEA 3-D PWR benchmark problem" using NESTLE code, which is based on the diffusion theory with finite difference (FDM) and nodal expansion method (NEM) solvers.

Russel D. Mosteller [11] has performed calculations using NESTLE advanced nodal code for four different types of reactors (PWR, Boiling Water Reactors - BWR, CANDU Heavy Water Reactors - HWR and High Temperature Gascooled Reactors - HTGR), validating the NESTLE code results for PWRs against measured data from PWR reactors.

Purdue University has performed the 3D calculation for the same benchmark problem by using the Purdue code PARCS [12], a US core simulator developed by Purdue University, which solves the two-group neutron diffusion equation utilizing the analytic nodal method (ANM).
In the present paper, the calculations for the specified benchmark were performed using a Multi-Group Monte Carlo method by MCNP code version MCNPX 2.7.0 [6] on one hand, and on the other hand to get some information on the range of errors in the deterministic codes resulting from space homogenization. The effective multiplication factor and power distribution for quarter core configuration were calculated in 2-D and 3-D models. The MCNP results are compared with the results of Milonga and PARK codes, in two and three dimensions, respectively.

\section{Methodology and Problem Specification}

The IAEA PWR problem is a very important standard benchmark problem developed to measure the performance of neutronics calculation methods. The problem conditions are specified in an ANL technical report [7]. It was submitted to IAEA by a group of experts from different organizations (CE, Ontario Hydro, Risø-Denmark, ORNL-US, KWU and GRS-Munich) in June 1976, and accepted for publication in June 1977[7]. The problem identifies two-group cross sections for two different fuel assemblies and reflector regions.

"One hundred and seventy seven fuel assemblies including nine fully rodded fuel assemblies and four partially rodded fuel assemblies compose the core. Sixty four reflector assemblies surround the core. The fuel assembly pitch is $20 \mathrm{~cm}$ and the active height of a fuel assembly is $340 \mathrm{~cm}$. The thickness of axial reflector is $20 \mathrm{~cm}$." [7] Figure (1) presents the radial quarter and axial core configuration a of IAEA PWR core. The corresponding homogeneous macroscopic cross sections are given in Table (1).
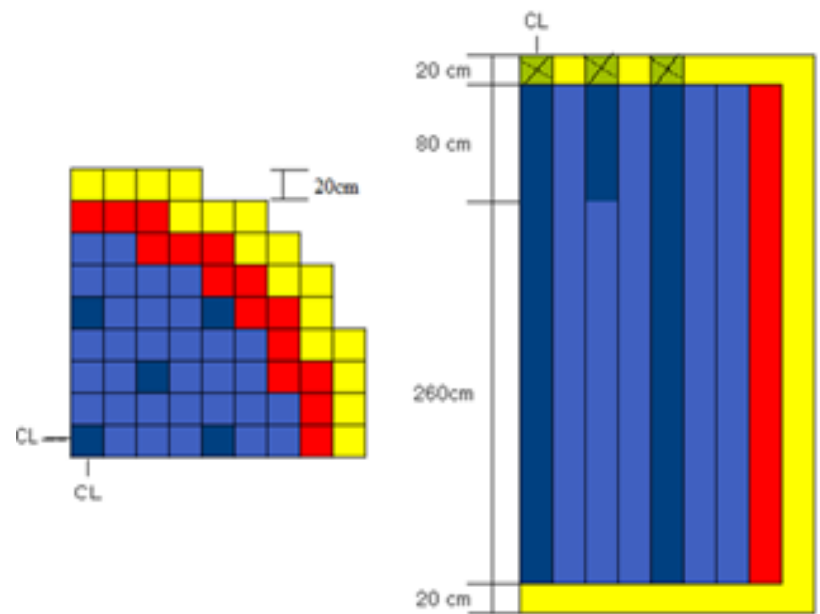

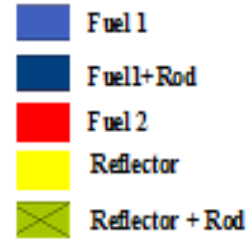

Figure (1): IAEA PWR radial and axial core configuration [7] 
Table (1): IAEA PWR two-group cross sections [7]

\begin{tabular}{|c|c|c|c|c|c|c|}
\hline Material & $\mathrm{D} 1$ & $\mathrm{D} 2$ & $\sum \mathrm{a} 1$ & $\sum \mathrm{a} 2$ & $\gamma \Sigma_{\mathrm{f}_{2}}$ & $\sum \mathrm{s} 1 \rightarrow 2$ \\
\hline Fuel 1 & 1.5 & 0.4 & 0.01 & 0.085 & 0.135 & 0.02 \\
\hline Fuel1+Rod & 1.5 & 0.4 & 0.01 & 0.13 & 0.135 & 0.02 \\
\hline Fuel 2 & 1.5 & 0.4 & 0.01 & 0.08 & 0.135 & 0.02 \\
\hline Reflector & 2.0 & 0.3 & 0.00 & 0.01 & 0.00 & 0.04 \\
\hline $\begin{array}{c}\text { Reflector + } \\
\text { Rod }\end{array}$ & 2.0 & 0.3 & 0.00 & 0.055 & 0.00 & 0.04 \\
\hline
\end{tabular}

In this paper, the calculations for the specified benchmark were performed using Monte Carlo code MCNPX [6]. The calculation carried out in two models, namely $2 \mathrm{D}$ and $3 \mathrm{D}$ evaluations, as follow:

The 2D calculation is carried out by comparing each of the following parameters: the maximum eigenvalue, the radial flux distributions traverses $\phi_{\mathrm{g}}(\mathrm{x}, 0)$ and $\phi_{\mathrm{g}}(\mathrm{x}, \mathrm{x})$, the value and location of maximum power density and the average subassembly powers $\quad P_{k}$ : $P_{k}=\frac{1}{V_{k}} \int_{V_{k}} \sum_{g} \gamma \Sigma_{f_{g}} . \emptyset_{g} d V$, where $\mathrm{V}_{\mathrm{k}}$ is the volume of the k-th subassembly and " $k$ " represents the fuel assembly number, numbered from 1 to 38 as shown in Figure (2).

The 3D calculation was completed by comparing each of the following parameters: the maximum eigenvalue, the axial power distribution and the average subassembly powers $\mathrm{P}_{\mathrm{k}}$.

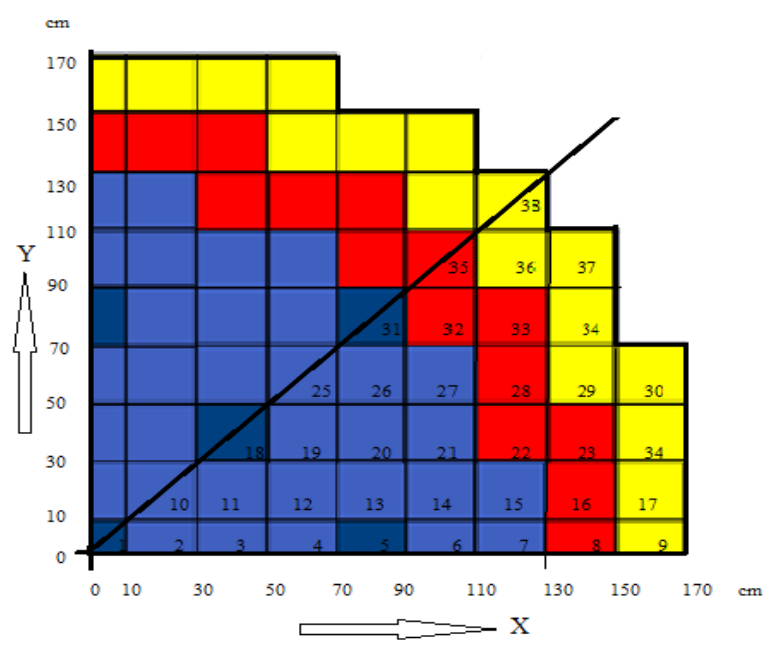

Figure (2): fuel core configuration: Upper octant: region assignments. Lower octant: fuel assembly identification

The MCNP results obtained in the 2D calculation were compared with the results given by the
Milonga code [9], while the MCNP results obtained in the 3D calculation were compared with the results given by the PARCS code [12]. For before mentioned results, the maximum and mean relative errors were given in this paper.

To assess the overall relative power distribution, the following collective percent error measures were selected:

- Average of the assembly relative power percent error $(A V G)-$ This is a very useful quantity that gives an overall idea of the assembly relative power distribution accuracy.

- Root Mean Square (RMS) of the zone power percent error distribution, measure weights higher percentages of errors than the smallest ones. Consequently, it gives a better assessment of the distribution of the percent errors than the AVG error measure can give.

- Mean Relative zone power per cent Error (MRE) - measure weights the percent error with the reference relative power, thereby linking the percent error distribution to the power distribution.

$A V G=\frac{\sum_{N}\left|e_{n}\right|}{N}$

$R M S=\sqrt{\frac{\sum_{N} e_{n}^{2}}{N}}$

$M E R=\frac{\sum_{N}\left|e_{n}\right| \cdot P_{n}}{N \cdot P_{\text {avg }}}$

Where $\mathrm{N}$ is the number of fuel assembly, $\mathrm{e}_{\mathrm{n}}$ is the calculated percent error for the $\mathrm{n}^{\text {th }}$ assembly power $\mathrm{P}_{\mathrm{n}}$, and $\mathrm{P}_{\text {avg }}$ is the average power of assemblies.

\section{Results and Discussions}

For fuel assembly design and whole core safety analysis the estimation of effective multiplication factor and power distribution are very important. In this paper, a multi-group Monte Carlo calculation has been performed in order to obtain the effective multiplication factor, the group fluxes, and the radial and axial assembly powers. 
The multi-group Monte Carlo calculations have been performed using the MCNPX transport code, both for 2D and 3D evaluations.

\section{I- Two dimensional model calculations:}

In this stage, the calculations was run with $1.0^{*} 10^{7}$ histories, yielding a $\mathrm{k}_{\text {eff }}$ of 1.03006 , with a standard deviation of $\sigma=11 * 10^{-5}$. The effective multiplication factor value calculated using MCNP code was compared with the one obtained using Milonga code, and are presented in Table (2). Moreover, the radial flux transverses $\emptyset_{\mathrm{g}}(\mathrm{x}, 0)$ and $\emptyset_{\mathrm{g}}(\mathrm{x}, \mathrm{x})$ were calculated (see Figs. 3 and 4) and then compared with the results obtained with Milonga code.

Table (2): Effective Multiplication factor

\begin{tabular}{|c|c|c|}
\hline MCNPX & Milonga & $\begin{array}{c}\text { Percent error for } \\
\mathrm{k}_{\text {eff }}\end{array}$ \\
\hline $1.03006( \pm 0.00011)$ & 1.02972184 & 0.033816 \\
\hline
\end{tabular}

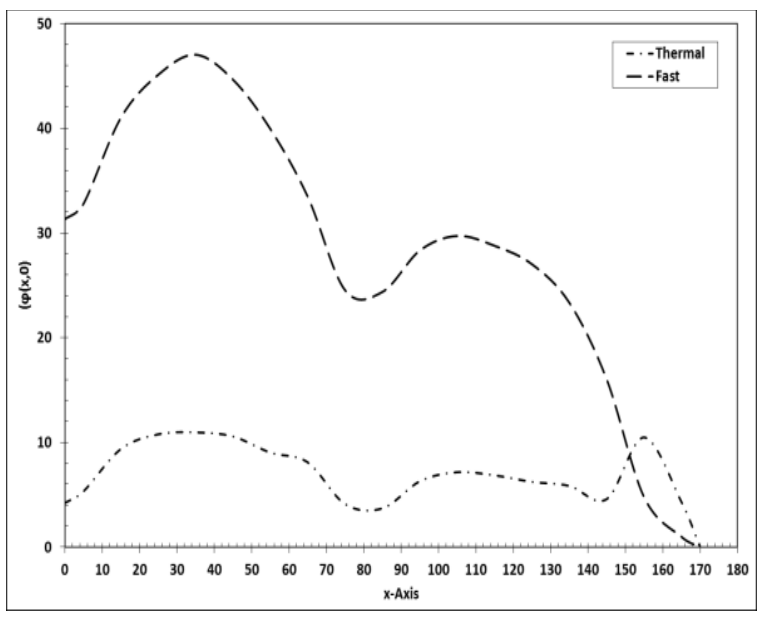

Figure (3): The radial flux traverses $\phi_{\mathrm{g}}(\mathrm{x}, 0)$

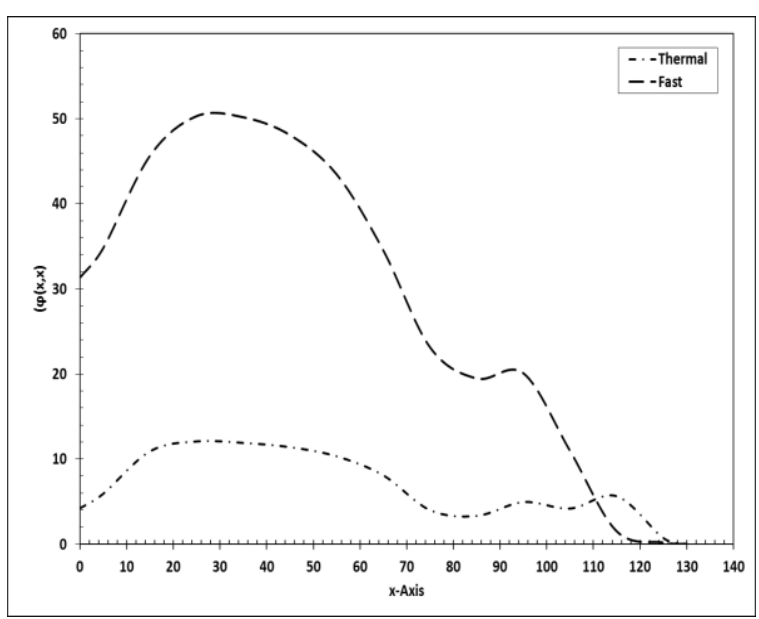

Figure (4): The radial flux traverses $\phi_{\mathrm{g}}(\mathbf{x}, \mathbf{x})$

Arab J. Nucl. Sci. \& Applic. Vol. 52, No. 1 (2019)
The calculated values of zone average thermal and fast group fluxes were compared with the same results of Milonga code, and the comparison is presented in Figs. (5 and 6) respectively, together with the relative deviation from the Milonga code results. The relative deviation of the MCNP average flux from the Milonga code average flux is also illustrated in Figure (7). The deviation is calculated as:

Relative Deviation $=$

$$
\frac{(\text { MCNP results })-(\text { Milonga results })}{\text { (Milonga results) }}
$$

Figure (8) shows the MCNPX results of radial relative power distributions for octant of the fuel. These results were also compared with the results given by Milonga code. Table (3) shows the maximum and minimum values for each of zone average thermal, zone average fast flux, relative power, and the relative deviation.

To assess the overall assembly power distribution, the average relative assembly power percent error (AVG), root mean square (RMS) of the relative assembly power percent error distribution, and mean relative assembly power percent error (MRE) were calculated using eqs.1, 2 and 3. Table (4) gives the Assembly relative power distribution error measures.

From presented Figures and Tables some aspects were noticed that could be summerized as follows: In Table (2), the percent error of $\mathrm{k}_{\mathrm{eff}}$ is less than $1 \%$, so the calculated results of effective multiplication factor using MCNPX is in a good agreement with Milonga results; moreover, the estimated standard deviation (S.D.) related to the results is equal to 0.00011, which is an acceptable value.

In Figs. (3 and 4), the maximum flux reaches 12.03, the peak being located at $\mathrm{x}=25.625, \mathrm{y}=$ 25.375.

Good agreements were observed in Figs. 5 and 6 and Table (3) between MCNP results and Milonga results. Very low maximum deviation was observed in Figure (7) for thermal and fast group flux, respectively. 
In Figure (8) it can be observed that the MCNPX values of radial assembly power distributions are in good agreement with the Milonga corresponding values. Also, from Table (3), the maximum and minimum relative power results given by MCNPX are reasonably close to the reference. The maximum relative power was 1.479 and 1.49 for MCNP and Melonga codes, respectively, while the minimum power was 0.469 for both codes. The maximum difference between MCNPX results and Milonga results was 0.024 .
The estimated relative error associated with the value of the maximum difference between the reference and the present results is within 0.0014; this value is reliable, as stated in the MCNPX user manual.

From Table (4) can be observed that the AVG, MRE and RMS error measures are less than $1 \%$; consequently, for all previous presented results, the errors in MCNPX calculation are very small.

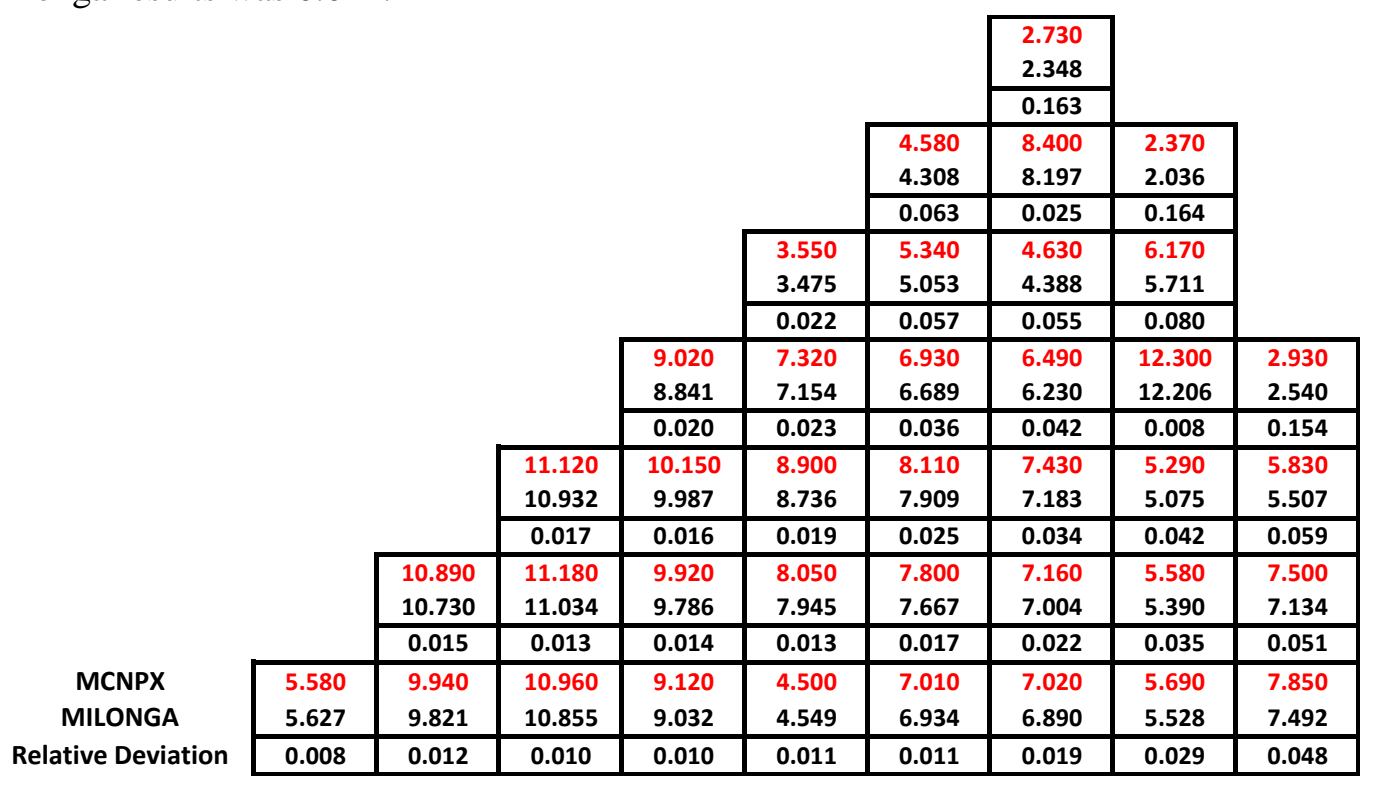

Figure (5): Zone average thermal group flux

\begin{tabular}{|c|c|c|c|c|c|c|c|c|c|}
\hline & & & & & & & $\begin{array}{l}0.680 \\
0.567 \\
\end{array}$ & & \\
\hline & & & & & & & 0.199 & & \\
\hline & & & & & & 15.070 & 3.940 & 0.590 & \\
\hline & & & & & & 13.931 & 3.937 & 0.503 & \\
\hline & & & & & & 0.082 & 0.001 & 0.173 & \\
\hline & & & & & 20.750 & 21.780 & 15.380 & 2.410 & \\
\hline & & & & & 20.336 & 20.664 & 14.329 & 2.295 & \\
\hline & & & & & 0.020 & 0.054 & 0.073 & 0.050 & \\
\hline & & & & 38.510 & 31.600 & 29.410 & 23.620 & 5.770 & 0.730 \\
\hline & & & & 37.699 & 30.857 & 28.391 & 22.449 & 5.861 & 0.619 \\
\hline & & & & 0.022 & 0.024 & 0.036 & 0.052 & 0.016 & 0.179 \\
\hline & & & 47.310 & 43.210 & 37.900 & 34.460 & 29.930 & 17.490 & 2.370 \\
\hline & & & 46.573 & 42.548 & 37.220 & 33.609 & 28.928 & 16.500 & 2.307 \\
\hline & & & 0.016 & 0.016 & 0.018 & 0.025 & 0.035 & 0.060 & 0.027 \\
\hline & & 46.430 & 47.640 & 42.340 & 34.760 & 33.260 & 30.340 & 20.540 & 3.100 \\
\hline & & 45.760 & 47.006 & 41.731 & 34.303 & 32.694 & 29.692 & 19.653 & 3.042 \\
\hline & & 0.015 & 0.013 & 0.015 & 0.013 & 0.017 & 0.022 & 0.045 & 0.019 \\
\hline MCNPX & 32.740 & 42.950 & 46.740 & 39.370 & 26.480 & 30.330 & 29.810 & 20.900 & 3.230 \\
\hline MILONGA & 33.093 & 42.405 & 46.245 & 38.974 & 26.750 & 29.972 & 29.279 & 20.116 & 3.181 \\
\hline Relative Deviation & 0.011 & 0.013 & 0.011 & 0.010 & 0.010 & 0.012 & 0.018 & 0.039 & 0.015 \\
\hline
\end{tabular}

Figure (6): Zone average fast group flux 


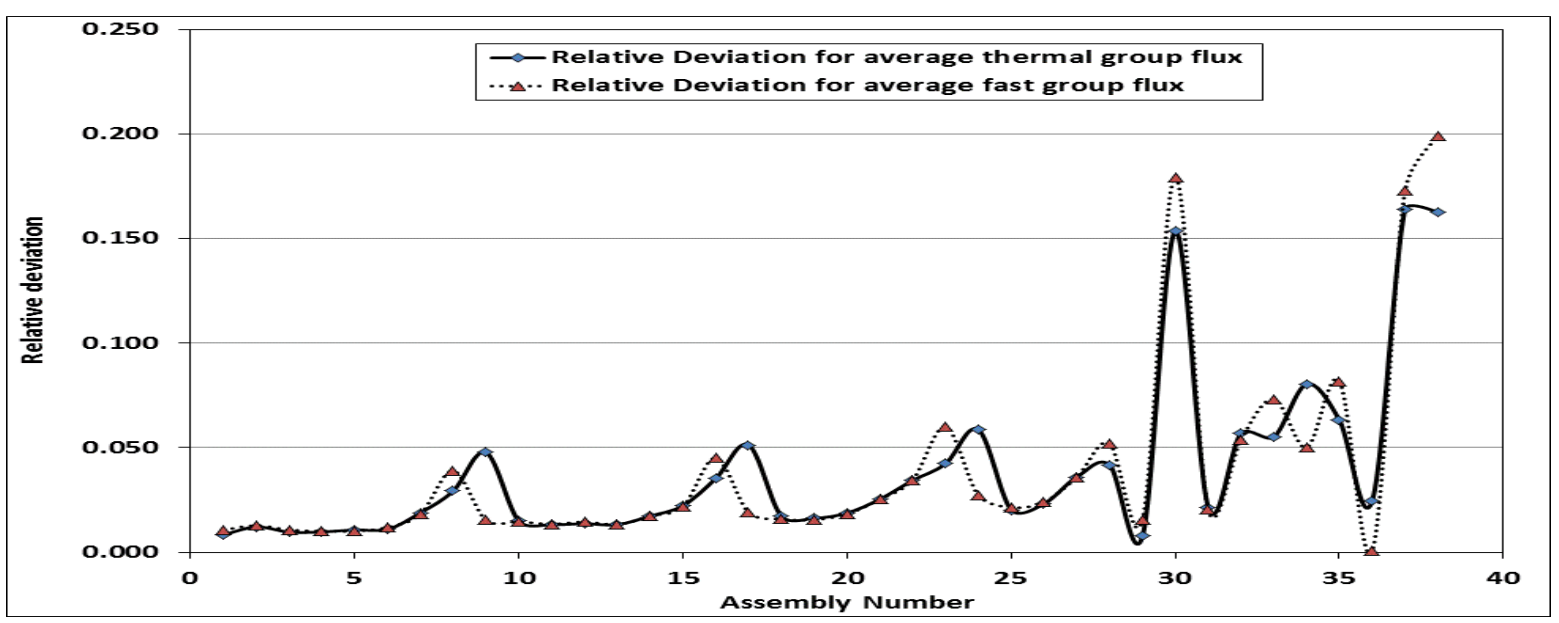

Figure (7): the relative deviation of MCNP average flux from Milonga

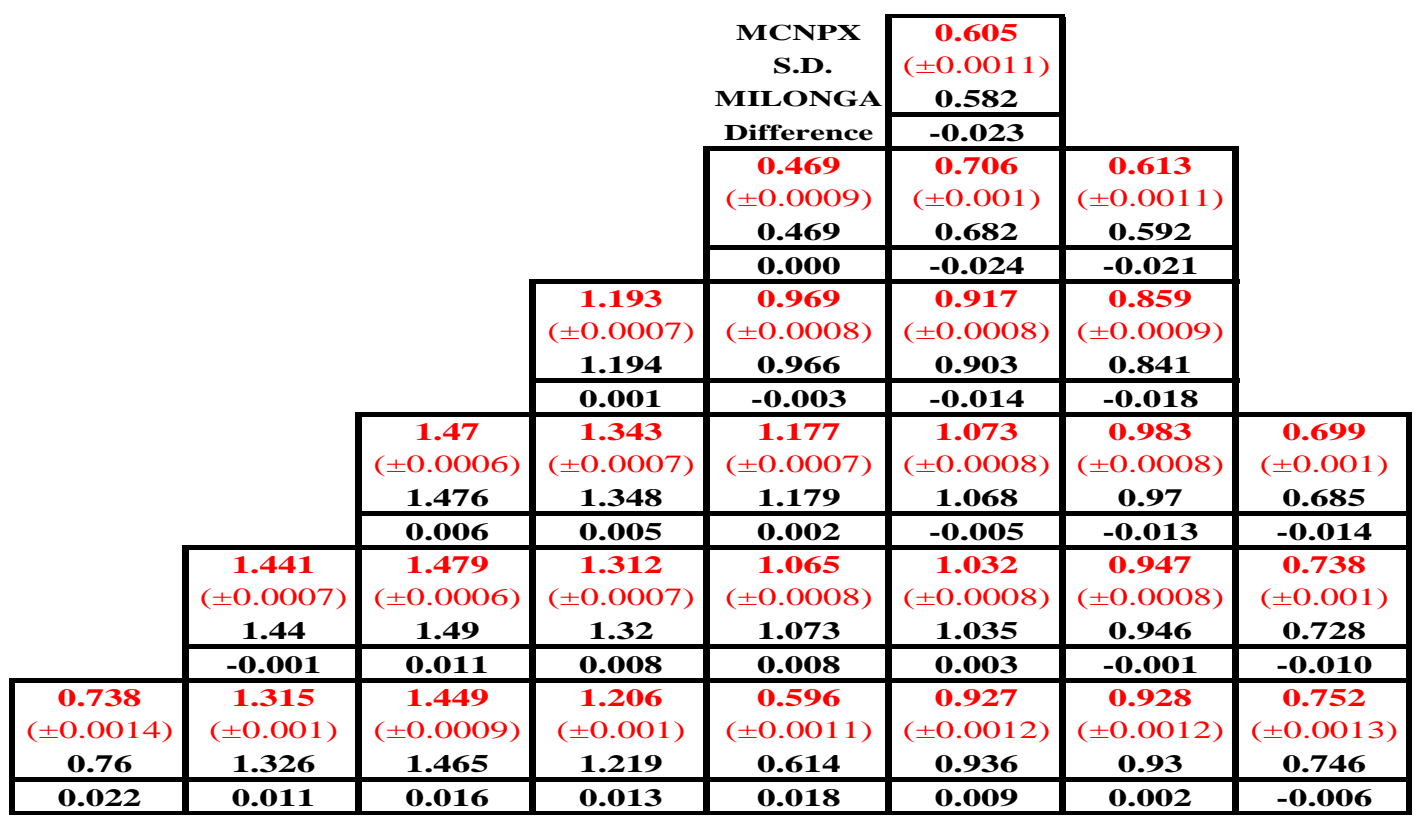

Figure (8): Radial assembly relative power distributions

Table (3): Relative deviation for the specific group flux and power distribution

\begin{tabular}{|l|c|c|c|c|c|c|}
\hline \multirow{2}{*}{} & \multicolumn{2}{|c|}{ Average Thermal group flux } & Average Fast group flux & \multicolumn{2}{c|}{ Relative Power } \\
\cline { 2 - 7 } & Maximum & Minimum & Maximum & Minimum & Maximum & Minimum \\
\hline MCNP results & 12.03 & 2.37 & 47.64 & 0.59 & 1.479 & 0.469 \\
\hline Milonga results & 12.206 & 2.036 & 47.006 & 0.503 & 1.49 & 0.469 \\
\hline Relative Deviation & 0.008 & 0.164 & 0.013 & 0.173 & 0.007 & 0.00 \\
\hline
\end{tabular}

Table (4): Relative power distribution error measures for MCNPX results

\begin{tabular}{|l|c|c|c|}
\hline & AVG & MRE & RMS \\
\hline Relative Power error & 0.010 & 0.009 & 0.012 \\
\hline
\end{tabular}




\section{II- Three-dimensional model calculations:}

The calculation was run with $1.2 * 10^{7}$ histories, yielding $\mathrm{a} \mathrm{k}_{\text {eff }}$ of 1.03030 , with a standard deviation of $\sigma=118^{*} 10^{-5}$. The effective multiplication factor calculated by MCNPX code was compared with the result given by PARCS code, the comparison is shown in Table 5. The results of axial power distribution are compared with the results of PARCS code and shown in Figure (9). The assembly relative power distributions of quarter core (power maps are normalized to 1) are shown in Figure (10). Table (6) illustrates the maximum and minimum values of relative power and the difference for PARCS and MCNPX calculations.

To assess the overall assembly power distribution, the (AVG), (RMS) and (MRE) percent error measures were calculated. Table (7) gives the error measures for $3 \mathrm{D}$ relative power distribution.

From the previous Figures and Tables, it can be noticed that:

- A low percent error of eigenvalue was observed in Table (5). Also, it must be taken into account that the estimated standard deviation of the effective multiplication factor was 0.00118 , which is an acceptable value.

- MCNPX 3D-axial power distribution values shown in Figure (9) are in very good agreement with the reference values in the center of assembly. But a small deviation can be noticed at the ends of the assembly.

- Figure (10) showed that the assembly relative power distributions calculated with MCNPX code agree well with those obtained with PARCS code, with a very small difference.

- From Table (6), the maximum and minimum relative power results of MCNPX are reasonably close to the reference values. The maximum relative power was 1.423 and 1.425 for MCNP and PARCS codes, respectively, while the minimum power was 0.463 and 0.477 for MCNP and PARCS codes, respectively. The maximum difference between MCNPX results and PARCS results was 0.112 .

- The estimated relative error associated with the value of the maximum difference between the reference values and the present results is within 0.0151 ; this value is reliable as stated in MCNPX user manual.

- From Table (7) it can be observed that the AVG, the MRE and the RMS error measures are less than $1 \%$, which is considered to be very good results.

- From all previous results, the errors in MCNPX results are very small. So, all results presented in this paper are accurate results for reactivity, flux and power distribution.

In almost all cases considered in this study, both for $2 \mathrm{D}$ and $3 \mathrm{D}$ evaluations, the MCNP calculated parameters of interest demonstrated a good compatibility of the computational modeling performed for the IAEA PWR problem with Melonga and PARK codes. Consequently, the present study results may be considered to be an accurate reference solution with MCNP Monte Carlo transport code, which can be used as reference for the IAEA PWR benchmark problem.

Table (5): the effective multiplication factor

\begin{tabular}{|c|c|c|c|}
\hline & MCNPX & PARCS & $\begin{array}{c}\text { Percent Error of } \\
\mathbf{k}_{\text {eff }}\end{array}$ \\
\hline $\mathbf{k}_{\text {eff }}$ & $\mathbf{1 . 0 3 0 3 0} \pm 0.00118$ & 1.029096 & $\mathbf{0 . 1 2 0 4}$ \\
\hline
\end{tabular}




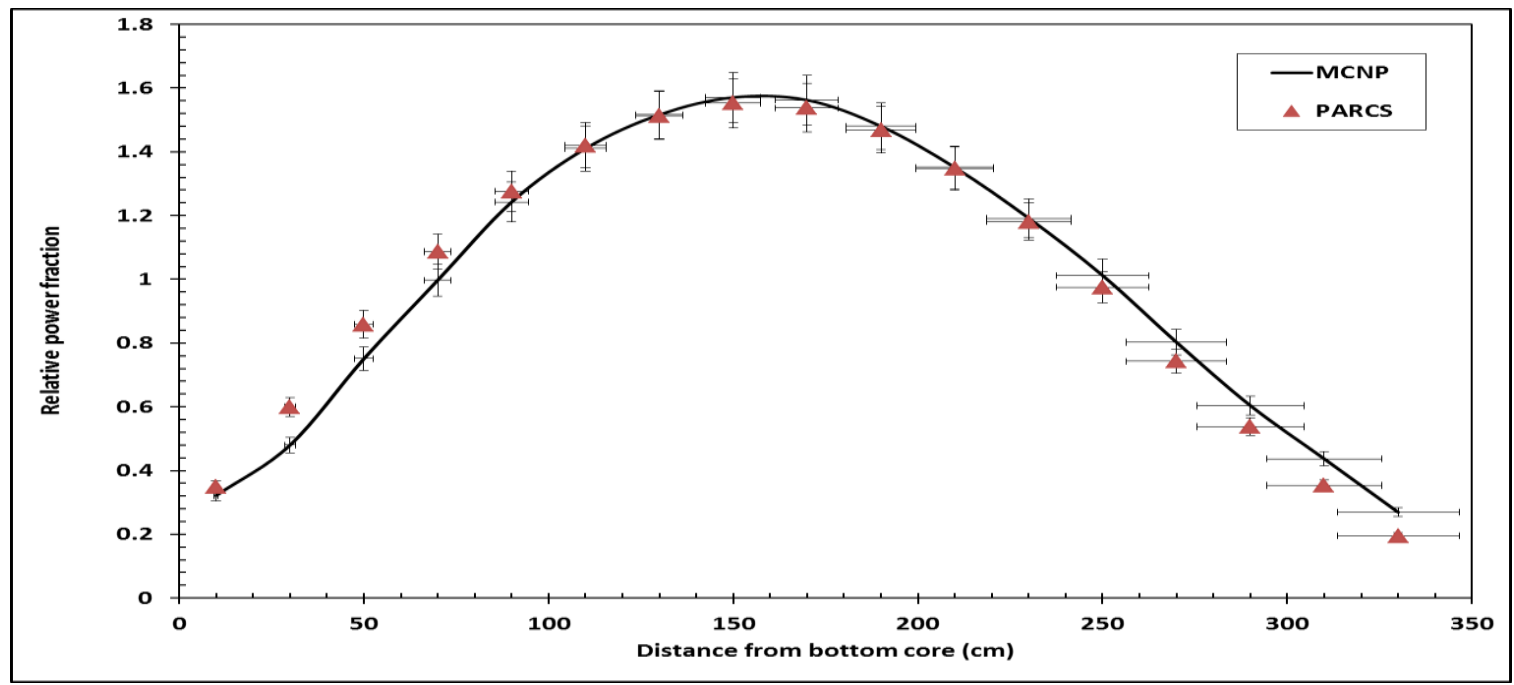

Figure (9): IAEA 3D-axial power distribution

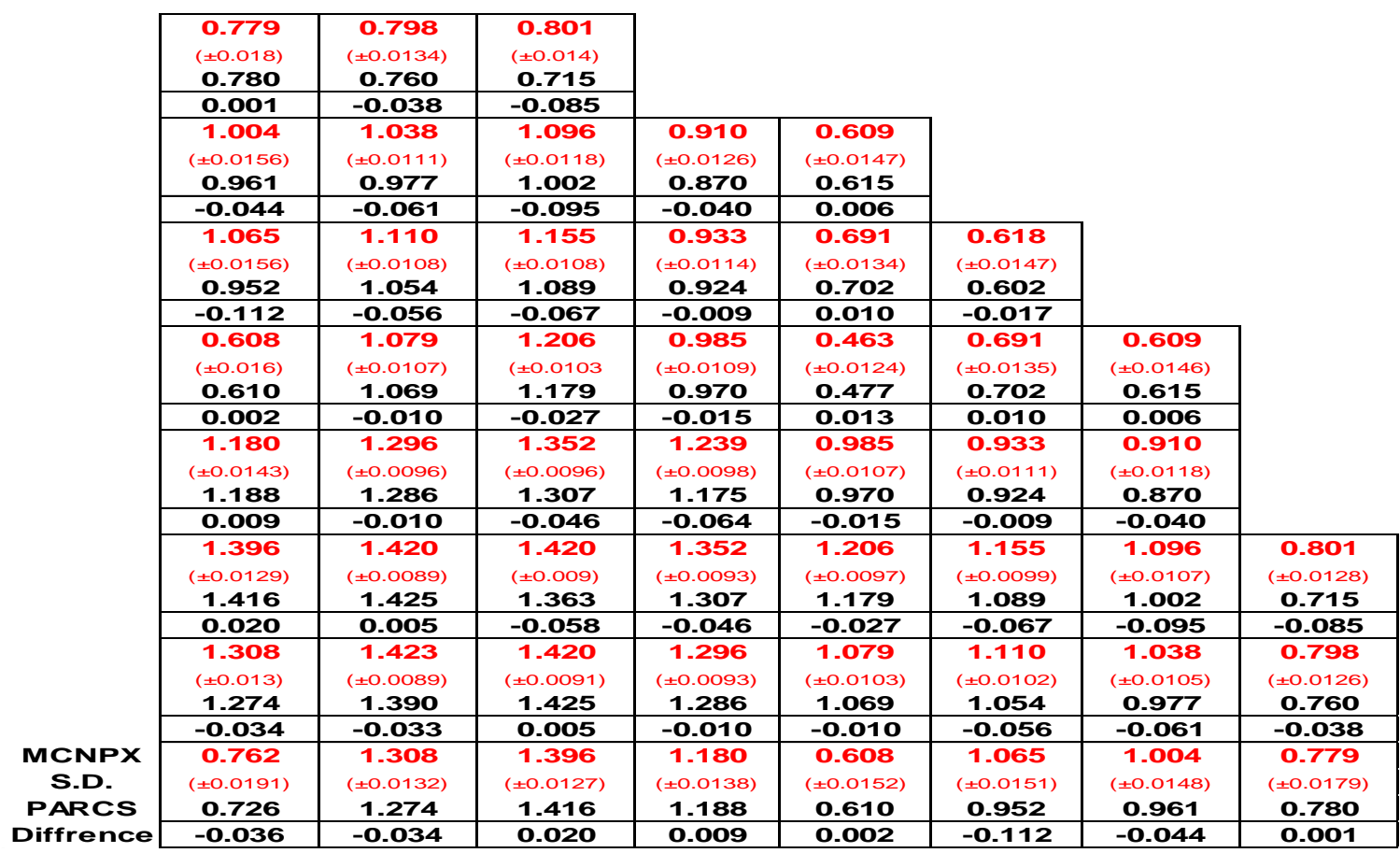

Figure (10): The assembly relative power distribution difference

Table (6): Difference for the specific relative power distribution

\begin{tabular}{|l|c|c|}
\hline \multirow{2}{*}{} & \multicolumn{2}{|c|}{ Relative Power } \\
\cline { 2 - 3 } & Maximum & Minimum \\
\hline MCNP results & 1.423 & 0.463 \\
\hline PARCS results & 1.425 & 0.477 \\
\hline Difference & 0.112 & 0.001 \\
\hline
\end{tabular}


Table (7): MCNPX Error measures for relative power distribution

\begin{tabular}{|c|c|c|c|}
\hline & AVG & MRE & RMS \\
\hline Relative Power error & 0.035 & 0.002 & 0.046 \\
\hline
\end{tabular}

\section{Conclusion and Discussion}

The aim of the present work is to set an accurate reference solution for the considered benchmark using the MCNP Monte Carlo transport code. It must be considered that the Monte Carlo methods are more accurate than the deterministic ones, especially because of detailed geometry without homogenization. The effective multiplication factor, the radial and axial assembly power distributions and zone average group fluxes were calculated. The results were compared against (deterministic) reference solutions, both for 2D and $3 \mathrm{D}$ evaluations. Moreover, for all the results in 2D and $3 \mathrm{D}$ calculations, the collective percent error measures were calculated. The AVG, MRE and RMS error measures were less than $1 \%$. The MCNP results are as good as, or better than, those obtained using the deterministic calculations, and as accurate as could be reasonably expected in a numerical solution. We can conclude that, the present results may be considered to be accurate reference solutions using Monte Carlo method and can be used as reference for the IAEA PWR benchmark problem.

\section{References}

1- S.S. Gorodkov, et.al, "Full--scale VVER-1000 model for Monte Carlo calculation of core neutron characteristics. MCU-PD and BIPR-7A results comparison", Proceedings of the nineteenth symposium of atomic energy research on WWER reactor physics and reactor safety, 2009.

2- M. Delpech, et.al, "Physics of BWR MOX Fuel Results of An International Benchmark Study by The OECD/NEA Nuclear Science Committee", Proceeding of Int. Conference GLOBAL 2001, Paris, 13 September, (2001).

3- H. J. Shim, et al., "Monte Carlo Adjoint Sensitivity and Uncertainty Analysis for Nuclear Data Covariance", ICNC 2011-
International Conference on Nuclear Criticality, Edinburgh, Scotland, Sep. 19-22, (2011).

4- Duderstadt, J.J. and Hamilton, L.J., "Nuclear Reactor Analysis", 1st Edition, John Wiley \& Sons, (1976).

5- J.F. Breismeister et al., "MCNP-A General Monte Carlo N-Particle Transport Code, Version 4A," LA-12625, Los Alamos National Laboratory, (1997).

6- D.B. Pelowitz, "MCNPX User's Manual, Version 2.6. 0," tech. rep., LA-CP-07-1473, April 2008.

7- Computational Benchmark Problem Committee for the Mathematics and Computation Division of the American Nuclear Society. Argonne Code Center: Benchmark problem book. Technical Report ANL-7416 Supplement 2, Argonne National Laboratory, (June 1977).

8- H.M. Omara, E.H. Amin and A.M. Khalaf, published in Arab Journal of Nuclear Science and Applications, 48(3), (95-102) 2015.

9- Theler, G., Clausse, A., Bonetto F.J., "Solution of the 2D IAEA PWR benchmark with the neutronic code Milonga", in Actas de la Reunión Anual de la Asociación Argentina de Tecnología Nuclear, XXXVIII,(2011).

10- Imelda Ariani and Doddy Kastanya," Evaluation of the IAEA 3-D PWR benchmark problem using Imelda Ariani and DoddyKastanya, "Evaluation of the IAEA 3-D PWR benchmark problem using NESTLE code"; P2SRMBATAN, (2004).

11- Russel D. Mosteller, " Static benchmarking of the NESTLE advanced nodal code", Proceedings of the Joint International Conference on Mathematical Methods and Supercomputing for Nuclear Applications, Vol. 2, pgs.1596-1605, (1997).

12- PARCS."IAEA3DPWRproblem",https://enginee ring.purdue.edu/PARCS/Code/TestSuite/Calcul ationMode/StandAloneMode/Eigenvalue/IAEA 3DPWR; (2014). 